\title{
Parents' perspectives on adolescent self-harm: qualitative study
}

Anna Oldershaw, Clair Richards, Mima Simic and Ulrike Schmidt

\section{Background}

Parents' perspectives on self-harm are considered important, but have not been explored.

\begin{abstract}
Aims
To gain perspective of parents of adolescents who self-harm on: (a) history of self-harm and health service provision; (b) their understanding and ability to make sense of self-harm behaviour; (c) emotional and personal impact; and (d) parent skills as carer and hope for the future.

\section{Method}

Interpretative phenomenological analysis was applied to semi-structured interviews with 12 parents of adolescents receiving treatment for self-harm in community child and adolescent mental health services.
\end{abstract}

\section{Results}

Parents commonly suspected and spotted self-harm prior to disclosure or service contact; however, communication difficulties and underestimating significance led to delays in addressing the behaviour. Parents struggled to understand and cope with self-harm.

\section{Conclusions}

Parents require advice and support from outside services to help them manage self-harming behaviour and its personal impact. This study suggests parents are early to spot signs of self-harm, indicating their key role in reaching young people in the community who remain unknown to health services.

\section{Declaration of Interest}

None. Funding detailed in Acknowledgements.
Approximately 170000 adolescents receive hospital treatment for self-harm annually in the UK. ${ }^{1}$ Yet, population samples suggest that just $12 \%$ of episodes result in hospital attendance. ${ }^{2}$ The elevated life-time suicide risk associated with self-harm ${ }^{3,4}$ means that finding a way to identify and support undetected cases in the community is crucial.

Engaging adolescents in services, even if they reach hospital, is challenging; adults with resolved self-harm recall difficulties in engaging with services as adolescents. ${ }^{5}$ Parents have a pivotal role in ensuring provision of treatment since mental health assessment for children under 16 years old requires their permission, and parental attitude and involvement influences a child's treatment adherence. $^{6}$ Thus, although National Institute for Health and Clinical Excellence (NICE) guidelines on self-harm treatment ${ }^{7}$ suggest that developing appropriate interventions for self-harm requires qualitative exploration of patients' experiences, parents' perspectives and experiences of adolescent self-harm also seem highly relevant in this context.

As yet, there has been very little research in this field. Raphael et $a l^{8}$ reported parental responses of anger, self-blame and helplessness following a one-off episode of self-harm for which the child was treated in an accident and emergency department. No study research has looked beyond the impact of initial disclosure or investigated the continuing effects of a child's repeated 'chronic' self-harm behaviour, and parents' perspectives on their role in seeking or maintaining help.

\section{Methods}

\section{Participants}

Parents of adolescents referred to a community child and adolescent mental health service (CAMHS) in Croydon, south London, for treatment of self-harm were approached for the study over a period of 11 months. One parent was recruited from a connected CAMHS.

\section{Inclusion criteria}

Parents were eligible for inclusion if they were a main carer living with an adolescent aged 13-18 years who had been referred to a
CAMHS. Self-harm was defined as any non-fatal self-injurious act purposefully carried out, regardless of underlying intent.

\section{Exclusion criteria}

Parents were excluded if they were unaware of their child's selfharm or if the young person had a serious comorbid illness, as parents would be unable to delineate views and feelings exclusively associated with self-harm.

Twelve parents (nine mothers, two fathers, one grandmother with a maternal role) agreed to participate. The approving research ethics committee (joint South London and Maudsley NHS Trust research ethics committee) did not require us to collect formal consent from adolescents for parents to be included; however, parents were advised to discuss their participation with their child. A further nine parents declined to take part in the study, including three parents who did not respond to a written invitation and six who declined after being approached in person. The online Tables DS1 and DS2 provide demographic information on the parents who agreed or refused participation, and the characteristics of the adolescents and their self-harm.

The main CAMHS involved in this study routinely offers parents of adolescents who self-harm the option of attending a parents' group or a one-off meeting with a CAMHS worker to discuss general aspects of self-harm. Eleven of the twelve participants were offered this type of support. Of these, four accepted: one parent attended the group and three parents requested an individual session. At the time of interview, no parents were engaged with any services outside of CAMHS.

\section{Interviews}

The semi-structured interviews lasted approximately $1 \mathrm{~h}$. Topic guides were developed in collaboration with the CAMHS clinicians who devised and ran the parents' groups. In order to check that questions were sufficiently open and wide ranging, once the initial guides had been drawn up they were reviewed by colleagues with experience of qualitative research in fields 
outside of CAMHS and by a parent of an adolescent who selfharms unconnected to the study. The topic guides were divided into four sections: history of self-harm; personal experience; making sense of self-harm and self-help; and improvements and hopes for the future. Questions posed were broad and open-ended such as 'Describe how and when you first found out about your son/daughter's self-harm behaviour'. All interviews were conducted face to face at the CAMHS centre by one researcher (A.O.) who had no previous relationship with participants. They were transcribed verbatim and pseudonyms given to protect participant identities. Individual summaries were sent to participants to allow them to reflect on key points, give feedback or expand. Only two parents (Mrs $\mathrm{E}$ and $\mathrm{Mr} \mathrm{J}$ ) responded to acknowledge that they had received their summary and both stated they were satisfied with the conclusions drawn.

\section{Analysis}

The data were imported into QSR NVivo 7 Software for Windows and analysed using interpretative phenomenological analysis. ${ }^{9}$ Interpretative phenomenological analysis is concerned with gaining insight into a person's subjective account of their experiences, rather than trying to objectively determine the facts, and is therefore useful for research seeking to explore participants' experiences, understanding and views. ${ }^{10}$ This inductive form of analysis recognises that the personal preconceptions and individual reflections of a researcher lead to an 'interpretative' account of the data.

Triangulation of data, achieved by two independent researchers (A.O. and C.R.) approaching the same sources and independently coding interviews, reduced the potential for researcher bias. The researchers began coding interviews while data collection was ongoing to ensure that data saturation was achieved before recruitment terminated.

Initially, four interviews were independently coded and an open coding session between the two researchers was used to confer on and list themes. Theme descriptions were drawn from the language of participants and all themes were included regardless of degree of prevalence. The remaining eight interviews were analysed using the index of prior themes to ensure consistency of labels and descriptions. Any new emerging themes were added to the index.

Interviews were constantly re-read and re-analysed to verify presence of new themes and validate relevance of original theme items, thus refining thematic categories. The systematic process of 'constant comparison'11 continued throughout the coding procedure and in a second session between the two researchers each theme's coded items were checked for consistency, interrater agreement and relevance. As part of this process, themes were further honed by grouping into hierarchies or subdividing as necessary.

\section{Results}

There were four key themes emerging from parents' accounts which are summarised below.

\section{The process of discovery}

The process of discovery was gradual, with waxing and waning levels of concern and a delicate interplay between parent and child as they negotiated the subject of self-harm. In the months leading up to self-harm disclosure, many parents had a suspicion about their child's behaviour, often spotting injuries. However, when directly confronted, all of the young people denied that they were harming themselves and made excuses about the cause (Appendix 1). Although the young person's explanations did not always fully allay parents' suspicion, most took a 'wait and see' approach, deciding not to push the issue but watch how the situation developed, hopeful that it might resolve itself.

For parents in this study, formal confirmation of their child's self-harm was often mediated by an outside agency, usually school. This disclosure happened both in partnership with the young person and with the agency making the disclosure on the child's behalf.

'It was just the three of us - Amy, the head-teacher and myself - and she got Amy to basically tell us, tell me, what had happened and that was the first time I found out.' (Mrs S)

Despite the initial desire to know, and outside agencies such as schools or primary services expressing their concern, the majority of parents reacted to suspicion or confirmation of self-harm by trying to 'brush it under the carpet'. They shared their child's ambivalence towards seeking treatment; they felt that the situation would resolve itself and saying little would be the best approach (Appendix 1).

Given this approach and attitudes towards self-harm, it is not surprising that most parents delayed instigation or acceptance of help and did not push their child to consider gaining professional advice. This process was generally only triggered after deterioration or 'accumulation' of problems, commonly trouble at school such as bullying or non-attendance.

'Things just gradually accumulated to the point where we realised we actually needed some external help.' (Mr J).

'It's basically just grown. It's got worse. Whereas we, you know, fingers crossed, everything crossed, you hope it's going to stop.' (Mr T)

The behaviour of outside agencies, namely schools or general practitioners (GPs), was suggested by parents to be a key factor in the timing of accessing help (Appendix 1). Parents discussed how the degree to which staff at school meetings or GP appointments advised or helped manage feelings about self-harm encouraged or curbed their help-seeking. For example, Mrs S accepted an immediate referral to CAMHS and reflected on the importance of the school's initial input in making this, apparently rare, choice (most parents interviewed refused the initial offer, accepting only the second or third). In contrast, poor support after initial disclosure hindered the help-seeking process (Mrs E). Although initially Mrs E's daughter had been willing to see the GP to discuss her self-harm, after his negative response, she tried to deny its existence. Consequently, parent and child began to sidestep the issue once more and it was not discussed again until problems deteriorated several months later.

\section{Making sense of self-harm}

Upon discovery of a child's self-harm, an instinctive response was for parents to question the motives and reasons behind it.

'The first thing I wanted to know was had something happened? What was her reason for why she'd done it?' (Mrs S)

There were usually no instant answers, and understanding and acceptance of self-harm was an ongoing gradual process. Even those with significant prior knowledge of self-harm struggled to understand and manage these behaviours in their own child.

I've worked with children who self-harm, but when it's on your own doorstep it's like a whole different kettle of fish and it's how you deal with it, and how it affects you and how you're going to handle it.' (Mr T)

In a reflection of earlier poor communication regarding disclosure, almost all parents said that their child would give them little or no explanation for their self-harm. However, when asked if they had any personal opinions on the causes, all identified problems they felt their child currently faced, usually citing several 
different potential causal factors. Identified causal factors fell into three categories: emotional difficulties, situational difficulties and personality factors.

(a) Emotional: 'Like any other person, if you're worried about something you look for a way to ease off your pain or whatever you're worried about.' (Mrs $\mathrm{H}$ )

(b) Situational: 'The whole thing underlying the self-harm was bullying.' (Mrs S)

(c) Personality: 'I think a sort of quite profound lack of selfesteem.' (Mr J); 'She's also a bit of a perfectionist as well, so you could almost say ... . she's a high achiever.' (Mrs S)

Within the context of these problems, parents recognised that self-harm served a purpose in their child's life. The function that it served depended on the core problem. For example:

(a) to cope with negative emotion: 'I did feel very very sad that she'd kind of was using this as a way of coping with her depression and low mood and unhappiness.' (Mrs B)

(b) for emotional expression: 'I think I've just realised that it's another way of letting go.' (Mrs H)

(c) to provide control: 'I can understand that it's some way of you having some sort of control over your pain, over your life, because you feel totally out of control when you're feeling so depressed or vulnerable or whatever.' (Mrs M)

Yet beyond an intellectual understanding, many parents felt they could not come to terms with their child's self-harming behaviour and understated its significance (Appendix 2). For example, the majority saw self-harm as a time-limited 'phase', and described their child's use of self-harm as influenced by peers or as a 'fashion'. Most parents struggled to accept self-harm and recognised the numerous 'typical' teenage behaviours that their child could alternatively have engaged in (e.g. drug or alcohol misuse) and felt regret that their child had 'opted' to self-harm. Ultimately, all parents felt that they could not fully understand or empathise with self-harm.

\section{Psychological impact of self-harm on parents}

Parents described strong and lasting emotional reactions to their child's behaviour. Although several different emotions were recalled, including shock, disappointment, guilt and fear, a persistent feeling of sadness and a sense of loss or bereavement were prominent (Appendix 3).

The psychological impact of self-harm was acute at the time of interview, irrespective of duration since disclosure, and several parents became tearful when discussing this topic. Parents described a sense of feeling helpless, lost, out of control and 'at sea' with their situation (Appendix 3).

Following referral to a CAMHS, parents had continued to struggle with the emotional impact of the self-harm and services were powerful in alleviating or heightening their distress. Parents who had accepted the offer of specific support felt that this was very beneficial. In contrast, the one participant without access to support (Mrs K) felt that this lack of specialist advice added to her distress (Appendix 3).

\section{Effect of self-harm on parenting and family}

Participants found that knowledge of their child's self-harm had influenced their behaviour as a parent and their experience of family life. They described 'walking on eggshells' around the adolescent, nervous of triggering an episode of self-harm. This affected their parenting style and ability to set limits and maintain boundaries (Appendix 4). Several parents found they were now constantly aware of what the young person was doing, both discreetly watching them from a distance, and providing increased overt attention and care-giving.

'It was like looking after a baby again. . . I was hiding the knives, I was hiding any pills . . I was knocking on her door every 5 minutes "You alright Gabi?" ' (Mrs M)

Many parents felt that they had to deny their own needs and make changes to or limit their lifestyle as a direct result of the selfharm. They found difficulties in balancing parenting and meeting the needs of other children, which heightened the psychological impact of self-harm by increasing parental burden, pressure and stress. However, parents did feel that the self-harm had resulted in some positive changes to family life by strengthening the parent-child relationship (Appendix 4).

\section{Discussion}

This study is the first to investigate parents' perceptions of a child's repetitive self-harm behaviour. We found that parents of adolescents who self-harm are sensitive to the behaviour and deeply affected by their experience.

Our study shows that parents may be more aware of their child's self-harm than adolescent self-reports of disclosure suggest. Parents usually raise their concerns with their children long before school or NHS services become aware of the problem. However, they may accept implausible explanations in the hope that things will improve spontaneously. Parents struggle to make sense of or accept self-harm, leaving them feeling 'at sea' with the situation, no longer knowing how to respond to their child and resulting in poor communication, altered parenting, increased parental burden, and a limited personal and social life.

Importantly, initial response of parents and input from schools and primary care affects timing of help-seeking. In the cases presented here, the help-seeking process was usually triggered only after an accumulation of problems independent of self-harm. Thus, it took more than 'just' self-harm to encourage parents to seek help. Parental attitude towards the self-harm behaviour, for example the perception that it was a phase, choice or fashion, may partly account for this. Equally, attitudes of GPs or school staff and their willingness to discuss self-harm with parents and give information influenced parental behaviour and the interval between disclosure and referral.

All parents said their main advice to others in their situation would be to seek help sooner than they had done. Their early identification of self-harm and attempts to take a 'wait and see' approach in the community suggests that other parents may be frequently recognising and managing self-harm in the family home without service input, indicating potential for parents to take a key role in reaching young people. Further research should investigate whether good advice and support, available from community resources without necessitating NHS or school involvement, could help parents to better understand, manage and cope with self-harm, and might decrease the likelihood of deterioration or encourage parents to make appropriate service contact earlier.

It is clear from parents' comments that, regardless of presence or quality of initial input, the offer of continued support is valued. Even when professional help is being provided for their child, parents felt they needed additional support to understand and accept self-harm, and give appropriate care.

\section{Previous research}

This study fits with previous research on the burden felt by parents when caring for someone with mental health problems ${ }^{12}$ and the strong emotional response aroused in parents who are 
carers. ${ }^{13}$ It suggests that the previously reported immediate emotional response felt by parents of children who self-harm ${ }^{8}$ is enduring. However, the limited expression of anger in our participants conflicts and may indicate that this emotion does reduce following recurrent episodes. The difficulties described by our participants reflect the communication problems previously shown to exist between children who self-harm and their parents. ${ }^{14}$

\section{Strengths and limitations}

This study included only parents from two CAMHS teams in south London and the opinions and experiences therefore reflect those of parents of adolescents referred to specialist services. Furthermore, as only half the parents approached agreed to participate and all were interviewed in a CAMHS setting, it is not clear how far the findings can be generalised, as results may be subject to sampling or response bias. However, the diversity of accounts was increased by using parents at different stages in the treatment process and, although the small number of participants may limit the study, data saturation was achieved and it is argued that smaller participant numbers are valued in interpretative phenomenological analysis for identification of subtle themes and meanings. ${ }^{15}$ This paper benefits from participant validation of themes using individual summaries. The reliability of themes is strengthened by the use of researcher triangulation.

Future research could aim to include parents who range more diversely, include other family members, and adolescents themselves, in order to gain a wider perspective on the impact of self-harm on family life and the reciprocal impact of family life on self-harm.

\section{Implications}

Teachers and primary healthcare practitioners should be aware of the needs of parents of adolescents who self-harm, in particular, of their feelings of helplessness and desire for advice. Parents may benefit if the time from discovery to referral is reduced and this reduction may be facilitated by improved personal understanding and appropriate guidance from schools and GPs. More research is needed to establish the exact nature of information that would most benefit parents and how this could be efficiently and effectively distributed. However, these parents felt that basic information in the first instance, from schools or GPs, would be useful.

Although individual needs of parents of young people attending CAMHSs should be recognised and continued support offered, it is interesting to note that less than half of the parents accepted CAMHS support, despite almost all parents stating that they needed this input. Thus, the mere offer of support may be more important than its content or provision. More research addressing the reasons why such resources are not utilised by parents and what can be done to redress this is required.

\section{Appendix 1}

\section{Parents' comments on the process of discovery}

confronting an adolescent over the signs of self-harm

'She'd told them that it was the rats - she had two pet rats at that stage - erm, so I asked her about it and she said "yes it's the rats", so I thought well you know, sounds a reasonable explanation, I'll accept that.' (Mrs B)

'She made up a cock and bull story ... and it didn't make any sense whatsoever, so I thought, ok, I'll go with that explanation and see where this goes from here.' (Mr T)

'[We] decided that our best course of action was not to make a big dramatic fuss and just let it unfold and just see if this evaporated. Erm, we realised that there was a sort of element of risk in that, but we weren't sure whether this was something that was deeply rooted, and erm ingrained as it were, or if this was something that was pretty temporary and would pass.' (Mr J)

\section{Parent reaction to disclosure}

'We kind of brushed that under the carpet... We try to ignore it really, to try and get on with life and hopefully she will stop doing it.' (Mrs P)

'There became a point where it was obviously more than just cutting . . . I didn't actually mention it really because I didn't wanna make too big a deal out of it.' (Mrs C)

Influence of outside agencies (schools or GPS) in timing of helpseeking

'The teacher at the school actually was really quite good. She actually gave me a lot of the background for self-harm, why girls self-harm ... she seemed to be quite clued up and in fact it was her that, she was the one that explained to me, a lot of it to me, because I had no idea what it [self-harm] was, what it meant ... I didn't feel as though I was floundering as much as I think I would have if I hadn't had her advice.' (Mrs S)

'The doctor put her off actually because I think we may have got further, but the doctor was more interested in how old she was, whether she was having sex and if she was using contraceptives and Kate came out very disillusioned.' (Mrs E).

\section{Appendix 2}

\section{Parents' comments on making sense of self-harm}

Self-harm as a 'fashion', 'phase' or a deliberate choice

'Part of me thinks, erm "well, that's what gloomy Goths do", you know, you sit down and talk about various ways to kill yourself and erm that's just a part of her adolescence and it will pass when she's ready.' (Mr J)

'I think it's just a little blip that'Il hopefully ... yeah she'll come round.' (Mrs P)

'First of all, my immediate reaction was erm she's just copying. She's just copying her friend.' (Mrs H)

'I almost feel that it is a fashionable thing to do. Do you understand what I mean by that? The girls have got themselves into a situation where it's trendy.' (Mrs F)

'I kind of expect teenagers to sort of surprise me. Probably self-harming wasn't the thing that I'd thought that she'd do ... maybe I would have been less surprised if she'd come home drunk or something.' (Mrs C)

'You know, wishing that she'd found another way, that she hadn't opted to do this.' (Mrs B)

'She could have found something else, maybe truanting from school, maybe doing something like being rude.' (Mrs H)

\section{Inability to empathise}

'I find that hard to empathise with because it just wouldn't be my way of dealing with it, erm but I can intellectually understand it.' (Mr J)

'I suppose what puzzles me is why anyone would actually hurt themselves in the first place ... it would never ever have occurred to me to stick anything into myself. It hurts!' (Mrs B)

'I don't understand it. I mean, I know why, but I don't understand.' (Mrs H)

\section{Appendix 3}

\section{Parents' comments on the psychological impact of self-harm}

\section{Sadness and loss}

'I was actually very sad, I was very sad for her [and] I am still . . . I mean that hasn't gone away.' (Mrs S)

'I miss, [gets tearful] I miss my little girl and that's, that's quite hard.' (Mr J)

'She was the loveliest little girl. It's like erm a bereavement really because that person's not there anymore.' (Mrs P) 


\section{Loss of control and helplessness}

'I've never had any experience of anyone self-harming. It's always something that happened to other people and I didn't really know how to cope with it. As a mother you always know how to help your child and make things better and I can't. I just fee out of my depth really.' (Mrs F)

'It was a case of, "crap, we have lost control. I don't know what it is to do".' (Mrs L)

'You know all these things go through your head and if you are without any frame of reference, you have no experience of this sort of thing, you're at sea.' (Mr J)

'I have felt a bit in a fog really.' (Mrs K)

'Hopelessness and bewilderment over one's children's unhappiness and not being able to sort things out.' (Mrs B)

\section{Influence of outside agencies on the psychological impact}

'CAMHS sort of advised me, even if my counsellor wasn't available someone has always come on the line and said, 'this is what we feel you should do' . . . It's very distressing when you feel very much on your own and you don't know what to do for the best. I know every situation's different but they've got more experience than I have. (Mrs F)

'It just helped to have somebody to sound off and you know, am I doing the right thing?' (Mrs E)

'The health professionals have got to deal with the patient haven't they, but I must say I have felt, I'm feeling, as though I'm trying to deal with this 24 hours a day and I don't know what to do for the best, so I don't know if what I'm doing and how I'm dealing with her is helping or if I might be making her worse! For all I know it might be totally the wrong, the wrong way of dealing with it. You feel like it's been taken out of you hands really without being given any kind of instruction.' (Mrs K)

\section{Appendix 4}

\section{Parents' comments on the effect of self-harm on family life}

Walking on eggshells

'It's almost like walking on eggshells a lot of the time to make sure you're not, not going to say anything that's going to upset her.' (Mrs S)

'She'd get annoyed with me or if I tell her off about something I'd then think "oh is she going to go and run upstairs and....".' (Mrs M)

'I don't want to push that button right and make her feel like she's done something terribly wrong ... . and then she'll go and do something again, so I don't say anything to her, which, I don't know, which is bad I suppose. I should really say something to her I think, but I don't know, I'm scared.' (Mr T)

\section{Denying own needs}

'I feel I've always got to be on the watch. So that, it makes it quite a pressure going places. I feel I've got to watch her to make sure that she's not getting distressed so yeah it does limit.' (Mrs K)

'I feel terrible to have to actually plan my life around whether or not she's going to be in a good mood or a bad mood.' (Mrs L)

'I've put off going back to work because of what's been happening with her.' (Mrs P)

\section{Imbalance in parental involvement between siblings}

'The only aspect I find difficult is the fact that she needs so much attention and you've got the other kids clambering wanting attention as well.' (Mrs S)

'I think Dawn felt a little bit left out ... it was just like oh Gabi's the golden child at the moment and she felt a little bit put out.' (Mrs M)

Positive effects on family life

'It's actually helped me break down some of those barriers because she's always coming up for cuddles now and actually I don't reject her anymore, and I think that's because I want to and I can. So that's . . I think that's a really positive thing. So now, you know, I get people coming up to me all the time, all four of them, even my 18year-old.' (Mrs S)

'It's made me a bit more upset, but at the same time, it's made me more wary of how they think, of how my own children are thinking and the concerns they have in their lives.' (Mr T)

Anna Oldershaw, MSc, King's College London, Institute of Psychiatry, London; Clair Richards, BSC, Mima Simic, MRCPsych, MSc, Croydon Child and Adolescent Menta Health Service, South London and Maudsley NHS Trust; Ulrike Schmidt, MRCPsych, $\mathrm{PhD}$, King's College London, Institute of Psychiatry, London

Correspondence: Anna Oldershaw, PO Box 059, Institute of Psychiatry, De Crespigny Park, London, SE5 8AF UK. Email: anna.oldershaw@iop.kcl.ac.uk

First received 2 Oct 2007, final revision 1 Feb 2008, accepted 9 Apr 2008

\section{Acknowledgements}

We are grateful to the Psychiatry Research Trust, and South London and Maudsley Research and Development funds for their support in financing this project. We thank Drs Laura Currin, Jenna Whitney, Frederique Van den Eynde and Olivia Kyriacou for their helpful comments on this paper and all the parents who took part in the study.

\section{References}

1 Barr W, Leitner M, Thomas J. Self-harm patients who take early discharge from the accident and emergency department. How do they differ from those who stay? Accid Emerge Nurs 2004; 12: 108-13.

2 Hawton K, Rodham K, Evans E, Weatherall R. Deliberate self-harm in adolescents: self report survey in schools in England. BMJ 2002; 325: 1207-11.

3 Owens D, Horrocks J, House A. Fatal and non-fatal repetition of self-harm. Systematic review. Br J Psychiatry 2002; 181: 193-9.

4 Hawton K, Zahl D, Weatherall R. Suicide following deliberate self-harm: long-term follow-up of patients who presented to a general hospital. Br J Psychiatry 2003; 182: 537-42.

5 Sinclair J, Green J. Understanding resolution of deliberate self-harm: qualitative interview study of patient's experiences. BMJ 2005; 330: 1112.

6 Clarke AR, Schnieden V, Hamilton BA, Dudley AM, Beard J, Einfeld SL, Buss R, Tobin M, Knowles M, Stevens G, Gibbs N. Factors associated with treatment compliance in young people following an emergency department presentation for deliberate self-harm. Arch Suicide Res 2004; 8: 147-52.

7 National Institute for Clinical Excellence. Guidelines for Depression in Children and Young People. NICE, 2005.

8 Raphael H, Clarke G, Kumar S. Exploring parents' responses to their child's deliberate self-harm. Health Educ 2006; 106: 9-20.

9 Smith JA. Beyond the divide between cognition and discourse. Using interpretative phenomenological analysis in health psychology. Psychol Health 1996; 11: 261-71.

10 Brocki JM, Wearden AJ. A critical evaluation of the use of interpretative phenomenological analysis in health psychology. Psychol Health 2006; 21: 87-101.

11 Pope C, Ziebland S, May M. Qualitative research in health care: analysing qualitative data. BMJ 2000; 320: 114-16.

12 Perkins S, Winn S, Murray J, Murphy R, Schmidt U. A qualitative study of the experience of caring for a person with bulimia nervosa. Part 1: The emotional impact of caring. Int J Eat Disord 2004; 36: 256-68.

13 Whitney J, Murray J, Gavan K, Todd G, Whitaker W, Treasure J. Experience of caring for someone with anorexia nervosa: qualitative study. Br J Psychiatry 2005; 187: 444-9.

14 Tulloch AL, Buzzard L, Pinkus Z. Adolescent-parent communication in selfharm. J Adolesc Health 1997; 21: 267-75.

15 Collins K, Nicholson P. The meaning of 'satisfaction' for people with dermatological problems. Reassessing approaches to qualitative health psychology research. J Health Psychol 2002; 7: 615-29. 